\title{
VALOR DIAGNÓSTICO DO HEMOGRAMA, UROCULTURA E HEMOCULTURA NA CANDIDOSE EXPERIMENTAL SISTÊMICA
}

\author{
Caroline Bohnen de Matos ${ }^{1}$, Claudia Giordani', Karina Affeldt Guterres ${ }^{1}$, Angelita do \\ Reis Gomes ${ }^{1}$, Rosema Santin ${ }^{1}$, Marlete Brum Cleff ${ }^{1}$ \\ 1 UFPEL \\ Correspondência: Caroline Bohnen de Matos: bohnencarol@gmail.com
}

\begin{abstract}
RESUMO: O presente estudo avaliou hemograma, proteínas plasmáticas totais (PPT), hemocultura e urocultura de ratos Wistar com candidose experimental sistêmica. Os animais $(n=12)$ foram inoculados com Candida albicans e acompanhados por 30 dias. A coleta de sangue e urina foi feita durante as necropsias. No eritrograma, $11,1 \%$ apresentaram anemia e $44,4 \%$ policitemia, enquanto que as PPT estavam aumentadas em $11,1 \%$ dos ratos. Em relação ao leucograma, $88,9 \%$ apresentaram leucopenia por neutropenia e linfopenia. Os neutrófilos segmentados tiveram um aumento dos valores relativos (28-48\%) em $66,7 \%$ dos animais quando comparados aos outros do grupo experimental (8-15\%). A cultura da urina apresentou-se positiva em $33 \%$ das amostras e a do sangue em $25 \%$, sendo que somente um animal com candidúria não apresentou hemocultura positiva. Os resultados demonstram que o hemograma completo, a urucultura e a hemocultura apresentaram-se de pouco valor no diagnóstico específico de candidose sistêmica experimental. Análises seriadas podem aumentar as chances de uro-hemoculturas positivas, e assim possibilitar a instituição de terapêutica precoce que possa beneficiar o paciente, e assim melhorar o prognóstico para a enfermidade.
\end{abstract}

Palavras-chave: avaliação laboratorial; Candida albicans; micose; ratos Wistar

\section{DIAGNOSTIC VALUE OF BLOOD COUNT, URINE AND BLOOD CULTURES IN EXPERIMENTAL SYSTEMIC CANDIDIASIS}

\begin{abstract}
This study evaluated blood count, total plasma protein (TPP), blood culture and urine of Wistar rats $(n=12)$ with experimental systemic candidiasis. The animals were inoculated with Candida albicans and monitored for 30 days. The collection of blood and urine was made during the autopsy. In red blood cell, was observed anemic in $11.1 \%$ and polycythemia in $44.4 \%$, while the PPT were increased in $11.1 \%$ of rats. In the WBC, $88.9 \%$ had severe neutropenia and lymphopenia. The segmented neutrophils had increase in relative values (28-48\%) in $66.7 \%$ of animals when compared to other experimental group (8-15\%). The urine culture were positive in $33 \%$ and blood samples in $25 \%$, only one animal with candida on urine had no positive blood cultures. The results demonstrate that the full blood count, the culture of blood and the culture of urine showed little value in specific diagnosis of experimental systemic candidiasis. Serial analyzes may increase the chances of positive blood and urine cultures, and thus enable the institution of early treatment that can benefit the patient, and thus improve prognosis.
\end{abstract}

Key Words: laboratory evaluation; Wistar rats; mycoses; Candida albicans 


\section{INTRODUÇÃO}

Candidose é a infecção causada por fungos do gênero Candida, onde o agente mais comum é a Candida albicans, porém existem outras espécies de crescente importância nos quadros clínicos, tais como: Candida tropicalis, Candida guillermondii, Candida glabrata, Candida krusei, entre aproximadamente 200 outras espécies. Colonizam normalmente diversos sítios anatômicos, como cavidade oral, tegumento, trato reprodutivo e digestório, além de apresentar-se em secreções brônquicas, urina, fezes e sangue, dentre outras (MIRADA et al., 2005; MENEZES et al., 2006; ÁLVARES et al., 2007; REIS-GOMES et al., 2013). Os casos de candidoses em animais tem $C$. albicans como a espécie mais frequentemente envolvida (VELASCO, 2000; MORETTI et al., 2004; JIN e LIN, 2005; JADHAV e PAL, 2006; KIVARIA e NOORDHUIZEN, 2007), no entanto, espécies como $C$. tropicalis, $C$. parapsilosis e C. krusei, também sido citadas como agentes de infecções em cães e gatos (MUELLER et al., 2002; PRESSLER et al., 2003; OZAWA et al., 2005; KIVARIA e NOORDHUIZEN, 2007).

As infecções sistêmicas por Candida spp. são descritas frequentemente em pacientes humanos, especialmente

nos imunocomprometidos, estimando-se uma taxa de mortalidade, por candidemia, em torno de 40-60\% (BLOT et al., 2002; VIUDES et al., 2002; GIOLO et al., 2010). Na medicina veterinária, encontramos infecções localizadas e sistêmicas relatadas ainda de forma ocasional, sendo estas principalmente em animais de companhia (MULLER et al., 2002; MORETTI et al., 2004; MORETTI et al., 2006, CLEFF et al., 2007).

Candidemias em pacientes humanos podem ser adquiridas por via exógena, através do contato das mãos de profissionais de saúde, com pacientes portadores de cateteres vasculares em posição central, implante de próteses contaminadas, bem como pela administração parenteral de soluções contaminadas (COLOMBO e GUIMARÃES, 2003). Outra forma de aquisição da infecção é por via endógena, devido a translocação do patógeno através do trato gastrointestinal, já que a colonização por Candida spp. neste sistema, sendo descrito em em até $70 \%$ da população (COLOMBO e GUIMARÃES, 2003). Na medicina veterinária, a candidemia tem sido pouco relatada (GERDING et al., 1994), mas a possibilidade de disseminação de Candida spp. para diversos tecidos é uma realidade cada vez mais próxima destes pacientes, sendo que, os profissionais devem estar preparados para 0 diagnóstico e administração da terapia adequada (COLOMBO et al., 2003).

Desta forma, o diagnóstico precoce de candidose sistêmica é fundamental para que o tratamento seja rapidamente instituído, aumentando, assim, a probabilidade de sucesso terapêutico. Uma das formas de diagnóstico da micose são isolamento e identificação das leveduras em amostras de sangue periférico, caracterizando candidemia (GIOLO et al., 2010). Para isolamento do agente é utilizada a hemocultura, e a identificação é realizada segundo as características bioquímicas e morfológicas (GIOLO et al., 2010).

Considerando a importância da rapidez no diagnóstico de candidose sistêmica, o trabalho teve como objetivo avaliar a frequência de urocultura e hemocultura positivas, assim como alterações hematológicas presentes em animais experimentais com candidose sistêmica. 


\section{MATERIAL E MÉTODOS}

Para a avaliação dos valores hematológicos, da urucultura e da hemocultura observados em casos de candidíase experimental sistêmica, foram utilizados 12 ratos Wistar adultos, mantidos em ambiente com condições controladas de temperatura e umidade, recebendo ração e água ad libitum, durante 30 dias. Sendo desenvolvido de acordo com as normas estabelecidas pelo Colégio Brasileiro de Experimentação Animal (COBEA).
A candidose experimental

sistêmica foi desenvolvida conforme protocolo estabelecido por Yamaguchi (1987), Anaissie et al. (1993) e Chami et al. (2004), sendo que a presença da enfermidades nos ratos foi comprovada através do retroisolamento do microorganismo dos órgãos internos e secreções, além de que foi observado a presença de infiltrados de $C$. albicans no exame histopatológico dos órgãos coletados.

O inóculo foi preparado com isolado de Candida albicans proveniente de caso clínico de candidose cutânea em cão (CLEFF et al., 2007), sendo este ajustado em aproximadamente $2 \times 10^{6} \mathrm{UFC} / \mathrm{mL}$, concentração a qual foi alcançada através da utilização da escala de Mc Farland, confirmada por plate. Os animais foram previamente anestesiados com xilazina $(10 \mathrm{mg} / \mathrm{kg})$ e quetamina $(80 \mathrm{mg} / \mathrm{kg})$, via intraperitoneal (Lapchik et al. 2009) e inoculados, via sistêmica, pela veia lateral da cauda, com $0,1 \mathrm{~mL}$ de suspensão fúngica, sendo acompanhados diariamente, por um período de 30 dias.

Realizou-se eutanásia em três animais por semana, com associação de xilazina e quetamina e tiopental, conforme metodologia estabelecida pelo Conselho Federal de Medicina Veterinária, Resolução $n^{\circ} 714$ de 20 de julho de 2002. O processamento hematológico foi realizado com amostras sanguíneas obtidas através de punção cardíaca, após anestesia. As amostras foram acondicionadas em tubos com EDTA e encaminhadas para posterior análise laboratorial. Todas as amostras de sangue foram processadas em até no máximo uma hora pós-coleta no laboratório de análise clínicas pertencente ao HCV-UFPel, sendo realizados exames de hemograma completo e Proteínas Plasmáticas Totais (PPT). A série vermelha (eritrócitos, hematócrito, concentração de hemoglobina), assim como a contagem total de leucócitos foi efetuada em contador automático de células específico para células das diferentes espécies animais $\left(\mathrm{Ce} / \mathrm{lm}{ }^{\circledR} \mathrm{CC}\right.$ 530). O diferencial leucocitário, por sua vez, foi obtido através da realização de esfregaços sanguíneos frescos corados com panótico (Newprov®) com a posterior análise microscópica de 100 células em aumento de 1000X. A dosagem de proteínas plasmáticas totais (PPT) foi determinada com a posterior leitura dos valores através do refratômetro.

Durante a necropsia, foi analisada a macromorfologia dos rins, fígado, encéfalo, bexiga, baço e pulmão em busca de alterações compatíveis com candidose e realizada a punção vesical. Uma alíquota do sangue e da urina, além de fragmentos dos órgãos, foram cultivados em duplicata, em placas contendo ágar Sabouraud dextrose acrescido de cloranfenicol incubadas a $35^{\circ} \mathrm{C}$ por $48 \mathrm{~h}$ para retroisolamento do agente. Após o crescimento realizou-se análise macrocoscópica e micromorfológica das colônias, além da prova do tubo germinativo e microcultivo em ágar fubá para avaliação da filamentização e formação de clamidioconídios e subcultivo em Agar CHRO Magar (seletivo e diferencial para identificar $C$. albicans através da coloração verde médio que a mesma apresenta neste meio), sendo possível 
através desses testes a confirmação da colonização dos tecidos e fluidos por Candida albicans.

\section{RESULTADOS E DISCUSSÃO}

Durante o período experimental, os animais apresentaram apatia, emagrecimento, nódulos cutâneos e alterações neurológicas como andar em círculos, lateralidade da cabeça e incoordenação. Os achados de necropsia revelaram comprometimento geral dos órgãos com lesões macroscópicas nodulares e esbranquiçadas, compatíveis com candidose sistêmica, sendo que os principais órgãos envolvidos foram rins (12/12), fígado (4/12), encéfalo (4/12) e bexiga (4/12). No cultivo para retroisolamento do agente, observou-se crescimento de colônias leveduriformes identificadas como C. albicans em todos os órgãos coletados, sendo principalmente em rins (12/12), encéfalo $(12 / 12)$ e fígado (11/12). As lesões foram compatíveis com os estudos de Anaissie et al. (1993), onde utilizou-se o mesmo modelo experimental com inoculação sistêmica de $C$. albicans.

Dos doze animais estudados, três que vieram a óbito ao longo do experimento, dois nas primeiras $72 \mathrm{~h}$ e 0 terceiro no quarto dia de experimento, não sendo possível a coleta para realização de exames complementares. Os animais que vieram a óbito apresentavam sinais clínicos neurológicos mais evidentes, incluindo alteração de deambulação e ataxia, além de inapetência e emagrecimento intenso. Cerca de 40 a $60 \%$ dos pacientes humanos com candidose disseminada morrem durante o período de internação (Colombo e Guimarães, 2003). Em um estudo com pacientes renais transplantados, observou-se três casos de candidose disseminada sendo que, dois pacientes vieram a óbito (MOISÉS NETO et al., 1997).
Em relação ao leucograma, seis animais avaliados $(66,7 \%)$, observou-se aumento dos neutrófilos segmentados $(28-48 \%)$, enquanto que os outros $(3 / 9)$ animais mantiveram valores entre $8 \%$ e $15 \%$. Em oito animais (88,9\%) observou-se leucopenia por neutropenia e linfopenia; sendo que quatro animais tinham contagem de leucócitos totais entre 4.000 e $5.000 \mathrm{~mm}^{3}$, três entre 2.000 e $3.000 \mathrm{~mm}^{3}$ e um animal apresentou 1.200 leucócitos totais. Os glóbulos brancos são responsáveis pelo combate às infecções, sendo que a contagem normal destas células em ratos Wistar fica entre 6.0 e $10.5 \times 10^{3}$ $\mathrm{mm}^{3}$ aproximadamente (Feldman et al., 2000). A leucopenia observada já era esperada devido a imunossupressão provocada nos animais experimentais para o desenvolvimento e manutenção da infecção (CHAMI et al., 2004).

As espécies do gênero Candida são responsáveis pelas principais causas de infecções fúngicas nosocomiais, podendo ocorrer a qualquer mudança no equilíbrio hormonal ou na depressão da resposta imune, seja por doença ou resultante de tratamentos (SILVA et al., 2014).

No eritrograma $11,1 \% \quad(n=1)$ apresentaram anemia e 44,4\% $(n=4)$ policitemia, enquanto que as proteínas plasmáticas totais (PPT) estavam aumentadas em 11,1\% (n=1) dos animais. A PPT aumentada e policitemia relativa são características de uma desidratação (Feldman et al., 2000). Segundo alguns autores, as leveduras podem causar destruição de eritrócitos pela produção de hemolisinas (LUO et al., 2004; GIOLO et al., 2010), sendo que Candida spp. pode causar hemólise parcial e/ou total (LUO et al., 2004; YIGIT et al., 2009). Rorig et al. (2009) demonstraram que $C$. albicans tem maior capacidade hemolítica quando comparadas a $C$. glabrata, $C$. parapsiolosis, C. tropicalis, C. Guilhermondii e C. krusei. 

sistêmica

Todos os animais estudados apresentaram envolvimento renal (12/12) com formação de microabcessos no córtex. A literatura nos evidencia que a disseminação hematógena das leveduras do gênero Candida ocorre através dos múltiplos abcessos formados ao longo do córtex renal (SILVA, 2008). Entretanto, nem todos os animais do experimento apresentaram candidúria, demonstrando, desta maneira, a necessidade de várias coletas de urina para se estabelecer o diagnóstico de certeza quando há suspeita de candidose invasiva. $\mathrm{Na}$ medicina humana, a urocultura é um exame de triagem comum e frequente nos pacientes expostos a fatores de risco, sendo que até $20 \%$ dos pacientes hospitalizados, nas unidades de terapia intensiva, podem apresentar candidúria ao longo de sua internação (COLOMBO e GUIMARÃES, 2007).

Alguns pesquisadores consideram a existência de Candida na urina como patogênica, independente da contagem, enquanto outros acreditam que a colonização exista em contagens superiores a $15 \mathrm{mil} / \mathrm{mL}$ (FIGUEREDO, 2010; SILVA et al., 2014).

A partir das amostras de urina coletadas dos animais experimentais, $33 \%(4 / 9)$ foram positivas na urocultura, enquanto que $25 \%(3 / 9)$ das amostras do sangue apresentaram-se positivas na hemocultura. Apenas um animal com candidúria não apresentou candidemia. Estudos avaliando hemocultura e urocultura em animais não foram encontrados na literatura consultada, entretanto os resultados concordam com dados de pacientes humanos, onde isolou-se Candida spp. de 100 pacientes hospitalizados avaliados através da urocultura, sendo identificado $C$. tropicalis em 53\% e C. albicans em 36\% destes casos (COLOMBO e GUIMARÃES, 2007). Bodey et al. (2002) em estudo epidemiológico de candidemia em

pacientes imunocomprometidos, identificaram, através da hemocultura, 236 casos de Candida spp, despertando assim, uma maior atenção para a obtenção do diagnóstico precoce, para assim instituir terapia imediata.

Em um estudo envolvendo 45.468 hemoculturas de quatro hospitais terciários de São Paulo, observou-se isolamento de Candida spp. em 4\% dos casos (COLOMBO e GUIMARÃES, 2007). O limitante é que a sensibilidade da hemocultura em infecções naturais é baixa, em torno de $50 \%$, com elevado número de casos falsos negativos (ALONSO-VALLE et al., 2003).

Segundo a literatura, o isolamento em cultura com posterior identificação das leveduras do gênero Candida ainda é a metodologia mais utilizada e disponível na maioria dos laboratórios clínicos (EGGIMANN et al., 2003; ELLEPOLA e MORRISON, 2005).

\section{CONCLUSÃO}

Com os resultados obtidos nesse estudo, podemos demonstram que 0 hemograma completo, urucultura e hemocultura apresentaram-se de pouco valor no diagnóstico específico de candidose sistêmica experimental, porém, análises seriadas podem aumentar as chances de urohemoculturas positivas, e assim possibilitar a instituição de terapêutica precoce que possa beneficiar 0 paciente, e assim melhorar o prognóstico.

\section{AGRADECIMENTOS}

CNPq e a CAPES pela concessão de bolsas de estudo e pelo financiamento do projeto. 


\section{REFERÊNCIAS}

ALONSO-VALLE, H.; ACHA, O.; GARCIAPALOMO, J.D. et al. Candidemia in terciary care hospital: epidemiology and factors influencing mortality. European Journal of Clinical Microbiology, v.22, n.4, p.254-257, 2003.

ÁLVARES, C.A; SVIDZINSKI, T.I.E.; CONSOLARO, M.E.L. Candidíase vulvovaginal: fatores predisponentesdo hospedeiro e virulência das leveduras. Jornal Brasileiro de Patologia e Medicina Laboratorial, v.43, n.5, p.319-327, 2007.

ANAISSIE, E.; HACHEM, R.; K-TIN-U, C. et al. Experimental Hematogenous Candidiasis Caused by C. krusei and C. albicans: Species Differences in Pathogenicity. Infection and Immunity, v.61, n.4, p.1268-1271, 1993.

BLOT, S.I.; VANDEWOUDE, K.H.; HOSTE, E.A. et al. Effects of nosocomial candidemia on outcomes of critically ill patients. American Journal of Medicine, v.113, n.6, p.480-485, 2002.

BODEY, G.P.; MARDANI, M.; HANNA, H.A. et al. The Epidemiology of Candida glabrata and Candida albicans Fungemia in Immunocompromised Patients with Cancer. American Journal of Medicine, v.112, n.5, p.380-85, 2002.

CHAMI, N.; CHAMI, F.; BENNIS, S. et al. Antifungal treatment with carvacrol and eugenol of oral candidiasis in immunosuppressed rats. Brazilian Journal of Infection Diseases, v.8, n.3, p.217-226, 2004.

CLEFF, M.B.; SILVA, G.M.; MEINERZ, A.R.M. et al. Infecção cutânea em cão por Candida albicans. Revista Veterinária e Zootecnia, v.2, p.14, 2007.

COLOMBO, A.L.; GUIMARÃES, T.

Epidemiologia das infecções hematogênicas por Candida sp. Revista Sociedade Brasileira de Medicina Tropical, v.36, n.5, p.599-607, 2003.

COLOMBO, A.L.; GUIMARÃES, T. Candidúria: uma abordagem clínica e terapêutica. Revista da Sociedade Brasileira de Medicina Tropical, v.40, n.3, p.332-337, 2007.

EGGIMANN, P.; GARBINO, J.; PITTET, D. Management of Candida species infections in critically ill patients. The Lancet Infectious Diseases, v.3, n.12, p.772-85, 2003.

ELLEPOLA, A.N.B.; MORRISON, C. Laboratory diagnosis of invasive candidiasis. Journal of Microbiology, v.43, p.65-84, 2005.
FELDMAN, B.F.; THOMAS, J.S.; ZINKL, J. et al. Schalm's veterinary hematology. 5ed. Philadelphia: Lippincott Williams \& Wilkins, 2000. 1344p.

FIGUEIREDO, J.A et al. Urologia Fundamental. Infecção urinária. São Paulo, São Paulo, ed. Planmark, 2010.

GERDING, P.A. et al. Ocular and disseminated candidiasis in an imunosuppressed cat. Journal of the American Veterinary Medical Association, v.204, p.1635-1638, 2004.

GIOLO, M.P.; SVIDZINSKI, T.I.E.

Fisiopatogenia, epidemiologia e diagnóstico laboratorial da candidemia. Jornal Brasileiro de Patologia e Medicina Laboratorial, v.46, n.3, p.225-234, 2010.

JADHAV, V.J.; PAL, M. Canine mycotic stomatitis due to Candida albicans. Revista Iberoamericana de Micologia, v.23, n.4, p.233234, 2006.

JIN, Y.; LIN, D. Fungal urinary tract infections in the dog and cat: a retrospective study (20012004). Journal of the American Animal Hospital Association, v.41, n.6, p.373-381, 2005.

KIVARIA, F.M.; NOORDHUIZEN, J.P.T.M. A retrospective study of the aetiology and temporal distribution of bovine clinical mastitis in smallholder dairy herds in the Dar es Salaam region of Tanzania. The Veterinary Journal, v.173, n.3, p.617-622, 2007.

LUO, G.; SAMARANAYAKE, L.P.; CHEUNG, B.P.K. et al. Reverse transcriptase polymerase chain reaction (RT-PCR) detection of HPL gene expression in Candida glabrata and its possible role in in vitro haemolysin production. Acta Pathologica, Microbiologica et Immunologica Scandinavica, v.112, n.4-5, p.283-290, 2004.

MENEZES, E.A.; MONTEIRO, M.N.R; PARENTE, T.M.A.; Cunha, F.A. et al. Freqüência e atividade enzimática de Candida albicans isolada da cavidade oral de pacients HIV - postivos em Fortalieza, Ceará. Jornal Brasileiro de Patologia e Medicina Laboratorial. v.42, n.4, p.253-256, 2006.

MIRANDA, K.C.; ARAUJO, C.R.; KHRAIS, C.H.A. et al. Identificação de leveduras do gênero Candida nas unhas e em descamação de pele em Goiânia (60), durante o ano de 2003. Revista de Patologia Brasileira, v.34, n.2, p.123-128, 2005.

MORETTI, A.; BONCIO, L.; POSTERARO, B. et al. Cocutaneous infection in a dog: pcr-reverse identification of $C$. tropicalis on skin biopsy. 
Journal of Medical Mycology, v.16, n.1, p.3036, 2006.

MORETTI, A.; POSTERARO, B.; BONCIO, L. et al. Diffuse cutaneous candidiasis in a dog.

Diagnostic by PCR-REA. Revista Iberoamericana de Micologia, v.21, n.3, p.139-142, 2004.

MOYSÉS, N.M.; COSTA, R.S.; REIS, M.A. et al. Candidíase em pacientes transplantados renais. Revista da Sociedade Brasileira de Medicina Tropical, v.30, n.6, p.485-491, 1997.

MUELLER, R.S.; BETTENAY, S.V.;

SHIPSTONE, M. Cutaneous Candidiasis in a dog, caused by Candida guilliermondii.

Veterinary Record, v.150, n.23, p.728-730, 2002.

OZAWA, H.; OKABAYASHI, K.; KANO, R. et al. Rapid identification of Candida tropicalis from canine cystitis. Mycopathologia, v.160, n.2, p.159-162, 2005.

REIS-GOMES, A.; MADRID, I.M.; MATOS, C.B. et al. Dermatopatias fúngicas: aspectos clínicos, diagnósticos e terapêuticos. Acta Veterinaria Brasilica, v.6, n.4, p.272-284, 2013.

RÖRIG, K.C.O.; COLACITE, J.; ABEGG, M.A. Producao de fatores de virulência in vitro por espécies patogênicas do gênero Candida.

Revista da Sociedade Brasileira de Medicina Tropical, v.42, p.225-227, 2009.

SILVA, A.K.F.; LISBOA, J.E.S.; BARBOSA, M.P.C.S. et al. Infecções urinárias nosocomiais causada por fungo do gênero candida: uma revisão. Caderno de Graduação-Ciências Biológicas e da Saúde-FITS, v.2, n.1, p.45-57, 2014.

VELASCO, M.C. Candidiasis and Cryptococcosis in birds. Seminars in Avian and Exotic Pet, v.9, n. 2, p.75-81, 2009.

PRESSLER, B.M.; VADEN, S.L.; LANE, I.F. et al. Candida spp urinary tract infections in 13 dogs and seven cats: predisposing factors, treatment, and outcome. Journal of the American Animal Hospital Association, v.39, n.3, p.263-270, 2003.

VIUDES, A.; PEMAN, J.; CANTON, E. et al. Candidemia at a terciary-care hospital: epidemiology, treatment, clinical outcome and risk factors for death. European Journal of Clinical Microbiology \& Infectious, v.21, p.767-74, 2002.

YAMAGUCHI, H. In: MIYAJI, M. Opportunistic Fungal Infections. Candidiasis in Animal
Models in Medical Mycology. CRC Press: Boca Raton, p.111-112 e p.144-151, 1987.

YIGIT, N.; AKTAS, E. Comparison of the efficacy of different blood medium in determining the hemolytic activity of Candida species.

Journal Medical Mycology, v.19, n.2, p.110-5, 2009. 